See discussions, stats, and author profiles for this publication at: https://www.researchgate.net/publication/272754362

\title{
GaN HEMT noise modeling based on $50-\Omega$ noise factor
}

Article in Microwave and Optical Technology Letters · April 2015

DOl: $10.1002 /$ mop. 28983

\section{CITATIONS}

24

6 authors, including:

Giovanni Crupi

Università degli Studi di Messina

156 PUBLICATIONS 1,866 CITATIONS

SEE PROFILE

Giorgio Vannini

University of Ferrara

255 PUBLICATIONS 2,431 CITATIONS

SEE PROFILE

Some of the authors of this publication are also working on these related projects:

Electrical Cryogenic Characterization of SAW resonators View project

Project High-power GaN HEMT characterization View project
Antonio Raffo

University of Ferrara

176 PUBLICATIONS 1,590 CITATIONS

SEE PROFILE 


\title{
GaN HEMT Noise Modeling based on 50-ohm Noise Factor
}

\author{
Giovanni Crupi ${ }^{1 *}$, Alina Caddemi ${ }^{1}$, Antonio Raffo ${ }^{2}$, \\ Giuseppe Salvo ${ }^{1}$, Andrea Nalli ${ }^{2}$, and Giorgio Vannini ${ }^{2}$ \\ ${ }^{1}$ DICIEAMA, University of Messina, 98166 Messina, Italy. \\ ${ }^{2}$ Department of Engineering, University of Ferrara, 44122 Ferrara, Italy. \\ *Corresponding author: Tel: +39 090 3977327; Fax: +39 090 3977571; E-mail: crupig@unime.it
}

\begin{abstract}
The extraction of a high-frequency equivalent circuit model plays a fundamental role for the development of any emerging transistor technology. Indeed, an equivalent circuit can provide a valuable support for microwave engineers to ensure a fast and reliable optimization of both device fabrication and circuit design. As far as Gallium Nitride (GaN) HEMTs are concerned, research efforts have been mostly focused on determining equivalent circuits able to reproduce their large-signal behaviour. Nevertheless, an increasing amount of interest is also being devoted to noise equivalent circuits, due to the interesting GaN technology noise performance. Within this context, the purpose of the present paper is to extract and fully validate an accurate noise model for GaN HEMTs based on a simple, fast, and reliable extraction procedure. The noise model is obtained by assigning an equivalent noise temperature to each resistor of the small-signal equivalent circuit. The accuracy of the extracted noise model is confirmed by the good agreement between measured and simulated high-frequency noise parameters.
\end{abstract}

Keywords: equivalent circuit; GaN HEMT; microwave measurements; noise parameters; scattering parameters. 
This is the peer reviewed version of the following article, which has been published in final form 2 http://dX.dol.org/10.1002/mop.28983. This article may be used for non-commercial purposes in accordance with Wiley Terms and Conditions http://olabout.wiley.com/WileyCDA/Section/id-828039.htm/\#terms.

\section{INTRODUCTION}

Nowadays, extensive attention is being paid to the HEMT based on GaN, primarily because of the outstanding physical properties of this wide-band-gap semiconductor for microwave high-power applications [1-11]. Although research studies have been mainly addressed to analyse the GaN HEMT in terms of power performance, a growing attention is being given also to its noise performance. Indeed GaN HEMTs achieve respectable microwave noise performance that is comparable to those of its Gallium Arsenide (GaAs) counterpart. Furthermore, the benefits of building high-power amplifiers (HPAs) and lownoise amplifiers (LNAs) in the same epitaxial material and eliminating the receiver protection circuitry (typically a PIN diode limiter), due to the excellent robustness of GaN transistors, have stimulated a significant interest in the GaN technology for low-noise applications [12-16]. With the aim of fulfilling the need for reliable equivalent circuit noise models, a number of studies have been recently published on the noise modelling for the GaN technology [17-25]. The proposed methods differ essentially for the chosen topology of the noise equivalent circuit and for the parameter extraction technique.

In the present paper, equivalent noise temperatures are assigned to each resistor of the GaN HEMT smallsignal equivalent circuit extracted from scattering (S-) parameter measurements. Thus, the extraction of the noise model is reduced to the determination of only the temperature associated to the intrinsic output resistance $\mathrm{T}_{\mathrm{ds}}$ [26], since the other resistance temperatures are selected to be equal to the ambient temperature, coherently with their physics-based contribution to thermal noise. The reported experimental results show that, in agreement with previously published studies for GaAs and Si transistors [27-30], the 50-ohm noise factor $\mathrm{F}_{50}$ of the tested GaN HEMT exhibits a behaviour as a function of the squared frequency that can be approximated by a first order fitting. This observation is of great importance because the most appropriate value of $\mathrm{T}_{\mathrm{ds}}$ can be successfully determined in order to enable the noise model to mimic the detected behaviour of $\mathrm{F}_{50}$. The effectiveness of this modelling technique for the GaN technology 
This is the peer reviewed version of the following article, which has been published in final form a http://dx.doi.org/10.1002/mop.28983. This article may be used for non-commercial purposes in accordance with Wiley Terms and Conditions http://olabout.wiley.com/WileyCDA/Section/id-828039.html\#terms.

is fully confirmed by the good agreement between the measured and simulated four noise $(\mathrm{N}-)$ parameters, which allow describing how the noise factor $\mathrm{F}$ (or noise figure NF when expressed in $\mathrm{dB}$ ) changes with the source reflection coefficient $\Gamma_{\mathrm{s}}$.

The paper is structured as follows. Section II consists of a brief description of the experimental set-up and the tested device. Next, Section III is aimed at presenting the modeling technique and discussing the experimental results. Finally, the main conclusive remarks of this study are given in the last section.

\section{EXPERIMENTAL MICROWAVE SET-UP AND TESTED DEVICE}

The photo of the experimental set-up for measuring both S- and N-parameters is reported in Fig. 1. The upper frequency limits of the used instrumentations for $\mathrm{S}$ - and $\mathrm{N}$ - parameter measurements are, respectively, $50 \mathrm{GHz}$ and $26.5 \mathrm{GHz}$. The main components of the set-up are: the vector network analyzer (Agilent E8364A PNA, $0.045 \mathrm{GHz}$ : $50 \mathrm{GHz}$ ), the smart noise source (Agilent N4002A SNS, $10 \mathrm{MHz}$ : 26.5 GHz), the input tuner (Maury MT-983BU01, $2: 26.5 \mathrm{GHz}$ ), the noise figure analyzer (Agilent N8975A NFA, $10 \mathrm{MHz}: 26.5 \mathrm{GHz}$ ), the low-noise amplifier (LNA Miteq JS4-02002600-33-10P, 2 GHz : 26.5 GHz), and two source-measure units (Keithley SMUs 2635A and 2611A) used for the DC biasing of the input and output ports [31].

The N-parameters are determined using the ATS Maury software according to a standard source-pull procedure, which is based on measuring the noise factor for different source impedances synthesized by the tuner. This procedure is based on expressing $\mathrm{F}$ as a function of the source reflection coefficient. The mathematical representation of this dependence requires four real quantities, known as noise parameters, and different sets of the noise parameters can be defined depending on the chosen formulation. However, these noise parameter sets represent equivalent ways of describing the same dependence and then wellknown conversion formulae allow passing from one set to another. One typical representation of $F\left(\Gamma_{\mathrm{s}}\right)$ is 
This is the peer reviewed version of the following article, which has been published in final form at http://dx.doi.org/10.1002/mop.28983. This article may be used for non-commercial purposes in accordance with Wiley Terms and Conditions http://olabout.wiley.com/WileyCDA/Section/id-828039.htm/\#terms.

given in terms of the minimum noise factor $F_{\min }$, magnitude and phase of the optimum source reflection coefficient $\Gamma_{\mathrm{opt}}$, and the equivalent noise resistance $\mathrm{R}_{\mathrm{n}}[32]-[36]$ :

$$
F=F_{\text {min }}+4 \frac{R_{n}}{Z_{0}} \frac{\left|\Gamma_{s}-\Gamma_{o p t}\right|^{2}}{\left|1+\Gamma_{o p t}\right|^{2}\left(1-\left|\Gamma_{s}\right|^{2}\right)}
$$

where the reference impedance $Z_{0}$ is usually $50 \Omega$. As can be easily seen from eq. (1), $F_{\min }$ is the minimum value of $\mathrm{F}$, which is achieved when $\Gamma_{\mathrm{s}}$ equals $\Gamma_{\mathrm{opt}}$, and $\mathrm{R}_{\mathrm{n}}$ represents how fast $\mathrm{F}$ increases as $\Gamma_{\mathrm{s}}$ departs from its optimum.

The investigated device is an AlGaN/GaN HEMT on Silicon Carbide (SiC) substrate with a gate length of $0.25 \mu \mathrm{m}$ and a gate width of $400 \mu \mathrm{m}$. Its interdigitated layout is based on eight fingers each with a length of $50 \mu \mathrm{m}$. A key benefit of using a multi-finger layout is given by the reduction of $\mathrm{R}_{\mathrm{g}}$, which allows obtaining an improvement of the noise performance. The DC output characteristics of the tested transistor are illustrated in Fig. $2\left(-3.5 \mathrm{~V} \leq \mathrm{V}_{\mathrm{GS}} \leq 0 \mathrm{~V}\right.$ with a constant step of 0.5$)$. The analysis of $\mathrm{S}$ - and $\mathrm{N}$ - parameters has been carried out at the bias condition corresponding to $\mathrm{V}_{\mathrm{DS}}=10 \mathrm{~V}$ and $\mathrm{I}_{\mathrm{DS}}=40 \mathrm{~mA}$. The S-parameters have been measured from $0.1 \mathrm{GHz}$ to $50 \mathrm{GHz}$ with a step of $0.1 \mathrm{GHz}$, while the N-parameters have been measured from $5 \mathrm{GHz}$ to $25 \mathrm{GHz}$ with a step of $1 \mathrm{GHz}$.

\section{MODEL EXTRACTION}

Fig. 3 presents the small-signal equivalent circuit that can be split into two main sections: intrinsic and extrinsic parts. The intrinsic section consists of seven elements $\left(C_{g s}, C_{g d}, C_{d s}, R_{g s}, R_{d s}, g_{m}\right.$, and $\left.\tau\right)$, which are 
This is the peer reviewed version of the following article, which has been published in final form af http://dx.doi.org/10.1002/mop.28983. This article may be used for non-commercial purposes in accordance with Wiley Terms and Conditions http://olabout.wiley.com/WileyCDA/Section/id-828039.html\#terms.

bias dependent. The extrinsic section is composed by eight elements $\left(C_{p g}, C_{p d}, L_{g}, L_{s}, L_{d}, R_{g}, R_{s}\right.$, and $\left.R_{d}\right)$, which are assumed to be bias-independent.

As illustrated in Fig. 4, the tested device exhibits a positive derivative of $\operatorname{Re}\left(\mathrm{Z}_{\mathrm{ij}}\right)$ versus the frequency (PDRZ) under "cold" pinch-off condition [37], due to the extrinsic capacitance contributions. Therefore, the extrinsic capacitances have been obtained by increasing their values from zero until the PDRZ effect disappeared from the de-embedded data, as proposed in [37], [38]. After removing the extrinsic capacitance contributions, the extrinsic resistances and inductances have been obtained from the slopes of the straight lines approximating $\omega^{2} \operatorname{Re}\left(\mathrm{Z}_{\mathrm{ij}}\right)$ and $\omega \operatorname{Im}\left(\mathrm{Z}_{\mathrm{ij}}\right)$ versus $\omega^{2}$, respectively (see Fig. 5) [38], [39]. Subsequently, the intrinsic elements have been calculated from the intrinsic admittance (Y-) parameters at the bias point of interest. The extracted values of the equivalent circuit elements are reported in Table I.

To obtain the corresponding noise model, equivalent noise temperatures have been assigned to the resistors of the circuit. All of these temperatures have been selected to be equal to the ambient temperature, with the exception of $T_{d s}$. Successively, by using a commercial circuit simulator, the value of $T_{d s}$ is easily searched for in order to reproduce accurately $\mathrm{F}_{50}$ versus the square of the frequency, as illustrated in Fig. 6.

\section{MODEL VALIDATION}

Fig. 7 shows the comparison between measured and simulated S-parameters for the tested GaN HEMT at $V_{D S}=10 \mathrm{~V}$ and $I_{D S}=40 \mathrm{~mA}$. The model reproduces very well the measurements over the full frequency range up to $50 \mathrm{GHz}$.

Likewise the case of the S-parameters, a good agreement between measurements and model simulations is achieved in terms of N-parameters over the broad frequency range from $5 \mathrm{GHz}$ to $25 \mathrm{GHz}$ (see Fig. 8). This result clearly confirms the validity of the equivalent circuit representation for the GaN HEMT noise modeling. 
This is the peer reviewed version of the following article, which has been published in final form 6 http://dx.doi.org/10.1002/mop.28983. This article may be used for non-commercial purposes in accordance with Wiley Terms and Conditions http://olabout.wiley.com/WileyCDA/Section/id-828039.htm/\#terms.

In addition, Fig. 9 illustrates the good agreement between the measured and simulated 3D elliptic paraboloid, which represents $\mathrm{NF}\left(\Gamma_{\mathrm{s}}\right)$. This representation, being based on a single plot, has the advantage of allowing a more straightforward and compact validation of the $\mathrm{N}$-parameter model at the frequency of interest. In the present case, to validate the model at high frequency, the analysis has been performed at 20 GHz. Analogously to the case of the noise figure, a 3D representation of the available gain $\mathrm{G}_{\mathrm{av}}$ as a function of the complex $\Gamma_{\mathrm{s}}$ can be defined in terms of S-parameters [35] or their corresponding gain parameters [40], [41] (see Fig. 10):

$$
G_{a v}=\frac{\left.\left(1-\left|\Gamma_{s}\right|^{2}\right) S_{21}\right|^{2}}{\left|1-S_{11} \Gamma_{s}\right|^{2}\left(1-\left|S_{22}+\frac{S_{12} S_{21} \Gamma_{s}}{1-S_{11} \Gamma_{s}}\right|^{2}\right)}
$$

It is worth noticing that since the noise model extraction is based on $\mathrm{F}_{50}$, the experimental data can be accurately measured by avoiding the presence of an expensive automatic broadband tuner with its sophisticated and time-consuming calibration, which strongly impacts the measurement accuracy at microwave frequencies especially when high reflection-coefficients have to be synthesized.

\section{CONCLUSIONS}

An equivalent circuit noise model has been extracted for a HEMT in GaN technology. The small-signal equivalent circuit has been used as the keystone for developing the noise model by assigning an equivalent noise temperature to each intrinsic and extrinsic resistor. The temperature associated to the intrinsic output resistance has been obtained by minimizing the difference between simulated and measured $50 \Omega$ noise 
This is the peer reviewed version of the following article, which has been published in final form a7 http://dx.doi.org/10.1002/mop.28983. This article may be used for non-commercial purposes in accordance with Wiley Terms and Conditions http://olabout.wiley.com/WileyCDA/Section/id-828039.html\#terms.

factor, while the other temperatures have been set to the ambient temperature. The achieved good agreement between measured and simulated N-parameters has confirmed the effectiveness of the described modeling approach for the GaN HEMT technology.

\section{ACKNOWLEDGMENTS}

This work was supported by the project PON 01_01322 PANREX with financial support by Italian MIUR and EMRP 'HF Circuits' project. 
This is the peer reviewed version of the following article, which has been published in final form 8 http://dX.dol.org/10.1002/mop.28983. This article may be used for non-commercial purposes in accordance with Wiley Terms and Conditions http://olabout.wiley.com/WileyCDA/Section/id-828039.htm/\#terms.

\section{REFERENCES}

[1] P. M. Cabral, J. C. Pedro, and N. B. Carvalho, Nonlinear device model of microwave power GaN HEMTs for high power-amplifier design, IEEE Trans Microwave Theory Tech 52 (2004), 2585-2592.

[2] O. Jardel, F. De Groote, T. Reveyrand, , J.-C. Jacquet, C. Charbonniaud, J.-P. Teyssier, D. Floriot, and R. Quéré, An electrothermal model for $\mathrm{AlGaN} / \mathrm{GaN}$ power HEMTs including trapping effects to improve large-signal simulation results on high VSWR, IEEE Trans Microwave Theory Tech 55 (2007), 2660-2669.

[3] P. Colantonio, F. Giannini, R. Giofrè, L. Piazzon, V. Camarchia, M. Pirola, G. Ghione, A. Cidronali, I. Magrini, G. Manes, R. Scholz and D. Knoll, From device characterization to system level analysis of dual band PA design in SiGe technology, Int J RF Microwave Comput-Aided Eng 18 (2008), 552-563.

[4] P. Colantonio, F. Giannini, R. Giofre, and L. Piazzon, Evaluation of GaN technology in power amplifier design, Microwave Opt Tech Lett 51 (2009), 42-44.

[5] G. Crupi, A. Raffo, D. M. M.-P. Schreurs, G. Avolio, V. Vadalà, S. Di Falco, A. Caddemi, and G. Vannini, Accurate GaN HEMT non-quasi-static large-signal model including dispersive effects, Microwave Opt Tech Lett 53 (2011), 692-697.

[6] A. Chini, V. Di Lecce, F. Fantini, G. Meneghesso, and E. Zanoni, Analysis of GaN HEMT failure mechanisms during DC and large-signal RF operation, IEEE Trans Electron Devices 59 (2012), 13851392.

[7] J.B. King and T.J. Brazil, Nonlinear electrothermal GaN HEMT model applied to high-efficiency power amplifier design, IEEE Trans Microwave Theory Tech 6 (2013), 444-454.

[8] L.-S. Liu, An improved empirical large-signal model for the GaAs- and GaN-based HEMTs, Int J RF Microwave Comput-Aided Eng 21 (2014), 343-352. 
This is the peer reviewed version of the following article, which has been published in final form a9: http://dx.doi.org/10.1002/mop.28983. This article may be used for non-commercial purposes in accordance with Wiley Terms and Conditions http://olabout.wiley.com/WileyCDA/Section/id-828039.html\#terms.

[9] G. Avolio, D. M. M.-P. Schreurs, A. Raffo, G. Crupi, A. Caddemi, G. Vannini, and B. Nauwelaers, Straightforward modeling of dynamic I-V characteristics for microwave FETs, Int J RF Microwave Comput-Aided Eng 24 (2014), 109-116.

[10] J.C. Cahuana, P. Landin, D. Gustafsson, C. Fager, and T. Eriksson, Linearization of dual-input Doherty power amplifiers, 2014 International Workshop on Integrated Nonlinear Microwave and Millimetre-Wave Circuits, Leuven, Belgium, April 2014, pp. 1-3.

[11] A. Raffo, G. Bosi, V. Vadalà, and G. Vannini, Behavioral modeling of GaN FETs: A load-line approach, IEEE Trans Microwave Theory Tech 62 (2014), 73-82.

[12] J. Moon, M. Micovic, A. Kurdoghlian, P. Janke, P. Hashimoto, W.-S. Wong, L. McCray, and C. Nguyen, Microwave noise performance of AlGaN-GaN HEMTs with small DC power dissipation, IEEE Electron Devices Lett, 23 (2002), 637-639.

[13] M. Rudolph, R. Behtash, R. Doerner, K. Hirche, J. Wurfl, W. Heinrich, and G. Trankle, Analysis of the survivability of GaN low-noise amplifiers, IEEE Trans Microwave Theory Tech 55 (2007), 37-43.

[14] Z. Cheng, Y. Cai, J. Liu, Y. Zhou, K. M. Lau, and K. J. Chen, 1.9-GHz low noise amplifier using high-linearity and low-noise composite-channel HEMTs, Microwave Opt Tech Lett 49 (2007), 13601362.

[15] S. Colangeli, A. Bentini, W. Ciccognani, E. Limiti, and A. Nanni, GaN-based robust low-noise amplifiers, IEEE Trans Electron Devices 60 (2013), 3238-3248.

[16] W. Chang, G. Jeon, Y.-R. Park, and J.-K. Mun, X-band MMIC low-noise amplifier MMIC on SiC substrate using 0.25- $\mu \mathrm{m}$ ALGaN/GaN HEMT technology, Microwave Opt Tech Lett 56 (2014), 96-99.

[17] C. H. Oxley, A simple approach including gate leakage for calculating the minimum noise figure of GaN HEMTs, Microwave Opt Tech Lett 33 (2002), 113-115.

[18] S. Lee, K.J. Webb, V. Tialk, and L.F. Eastman, Intrinsic noise equivalent-circuit parameters for AlGaN/GaN HEMTs, IEEE Trans Microwave Theory Tech 51 (2003), 1567-1577. 
This is the peer reviewed version of the following article, which has been published in final form 10 http://dx.doi.org/10.1002/mop.28983. This article may be used for non-commercial purposes in accordance with Wiley Terms and Conditions http://olabout.wiley.com/WileyCDA/Section/id-828039.html\#terms.

[19] C. Sanabria, H. Xu, T. Palacios, A. Chakraborty, S. Heikman, U. Mishra, and R. York, Influence of epitaxial structure in the noise figure of AlGaN/GaN HEMTs, IEEE Trans Microwave Theory Tech 53 (2005), 762-769.

[20] X. Cheng and Y Wang, A new analytical high frequency noise parameter model for AlGaN/GaN HEMT, Solid-State Electron 54 (2010), 1300-1303.

[21] Z.H. Liu, G.I. Ng, and S. Arulkumaran, Analytical modeling of high-frequency noise including temperature effects in GaN HEMTs on high-resistivity Si substrates, IEEE Trans Electron Devices 57 (2010), 1485-1491.

[22] T. Ross, G. Cormier, K. H, and R. E. Amaya, Particle swarm optimization in the determination of the optimal bias current for noise performance of gallium nitride HEMTs, Microwave Opt Tech Lett 53 (2011), 652-656.

[23] M. Rudolph and R. Doerner, Towards a large-signal noise model for GaN HEMT devices, 2013 European Microwave Integrated Circuits Conference, Nuremberg, Germany, October 2013, 484-487.

[24] M. Rudolph and R. Doerner, Bias-dependent Pospieszalski noise model for GaN HEMT devices, 2014 German Microwave Conference, Aachen, Germany, March 2014, pp 1-4.

[25] S. Colangeli, A. Bentini, W. Ciccognani, and E. Limiti, Polynomial noise modeling of silicon-based GaN HEMTs, Int J Numer Model 27 (2014), 812-821.

[26] M. W. Pospieszalski, Modeling of noise parameters of MESFET's and MODFET's and their frequency and temperature dependence, IEEE Trans Microwave Theory Tech 37 (1989), 1340-1350.

[27] G. Dambrine, H. Happy, F. Danneville, and A. Cappy, A new method for on wafer noise measurement, IEEE Trans Microwave Theory Tech 41 (1993), 375-381.

[28] J. Gao, C.L. Law, H. Wang, S. Aditya, and G. Boeck, A new method for pHEMT noise-parameter determination based on $50-\Omega$ noise measurement system, IEEE Trans Microwave Theory Tech 51 (2003), 2079-2089. 
This is the peer reviewed version of the following article, which has been published in final form $1 \mathrm{ll}$ http://dX.dol.org/10.1002/mop.28983. This article may be used for non-commercial purposes in accordance with Wiley Terms and Conditions http://olabout.wiley.com/WileyCDA/Section/id-828039.html\#terms.

[29] A. Caddemi and G. Crupi, On the noise measurements and modeling for on wafer HEMTs up to 26.5 GHz, Microwave Opt Tech Lett 52 (2010), 1799-1803.

[30] G. Crupi, A. Caddemi, D.M.M.-P. Schreurs, W. Wiatr, and A. Mercha, Microwave noise modeling of FinFETs, Solid-State Electron 56 (2011), 18-22.

[31] A. Caddemi, G. Crupi, E. Fazio, S. Patanè, and G. Salvo, Remarks of an extensive investigation on the microwave HEMT behavior under illumination, IEEE Microwave Wirel Compon Lett 24 (2014), 102-104.

[32] A. Caddemi, G. Martines, and M. Sannino, HEMT for low noise microwaves: CAD oriented modeling, IEEE Trans Microwave Theory Tech 40 (1992), 1441-1445.

[33] J.-M. Collantes, R. D. Pollard, and M. Sayed, Effects of DUT mismatch on the noise figure characterization: a comparative analysis of two Y-factor techniques, IEEE Trans Instrum Measurement 51 (2002), 1150-1156.

[34] G. Crupi and D. M. M.-P. Schreurs, Microwave de-embedding: from theory to applications. Oxford, UK: Academic Press, 2013.

[35] Fundamentals of RF and Microwave Noise Figure Measurements, Agilent Application Note 57-1 (2010).

[36] G. Crupi, D. M. M.-P. Schreurs, J.-P. Raskin, and A. Caddemi, A comprehensive review on microwave FinFET modeling for progressing beyond the state of art, Solid-State Electron 80 (2013), $81-95$.

[37] G. Crupi, D. M. M.-P. Schreurs, A. Caddemi, A. Raffo, F. Vanaverbeke, G. Avolio, G. Vannini, and W. De Raedt, High-frequency extraction of the extrinsic capacitances for GaN HEMT technology, IEEE Microwave Wirel Compon Lett 21 (2011), 445-447. 
This is the peer reviewed version of the following article, which has been published in final form 12 http://dx.doi.org/10.1002/mop.28983. This article may be used for non-commercial purposes in accordance with Wiley Terms and Conditions http://olabout.wiley.com/WileyCDA/Section/id-828039.html\#terms.

[38] G. Crupi, D. M. M.-P. Schreurs, A. Caddemi, A. Raffo, F. Vanaverbeke, G. Avolio, G. Vannini, and W. De Raedt, In-deep insight into the extrinsic capacitance impact on GaN HEMT modeling at millimeter-wave band, Int J RF Microwave Comput-Aided Eng 22 (2012), 308-318.

[39] G. Crupi, D.M.M.-P. Schreurs, A. Raffo, A. Caddemi., and G. Vannini, A new millimeter wave small-signal modeling approach for pHEMTs accounting for the output conductance time delay, IEEE Trans Microwave Theory Tech 56 (2008), 741-746.

[40] K. Hartmann, W. Kotyczka, and M.J.O. Strutt, Experimental gain parameters of three microwavebipolar transistors in the 2- to 8-GHz range, Proc IEEE 59 (1971), 1720-1721.

[41] A. Anastassiou and M.J.O. Strutt, Experimental gain and noise parameters of microwave GaAs FET's in the L and S bands, IEEE Trans Microwave Theory Tech 21 (1973), 419-422. 
This is the peer reviewed version of the following article, which has been published in final form 13 http://dX.doi.org/10.1002/mop.28983. This article may be used for non-commercial purposes in accordance with Wiley Terms and Conditions http://olabout.wiley.com/WileyCDA/Section/id-828039.html\#terms.

\section{FIGURE CAPTIONS}

Figure 1 Photo of the experimental set-up for S- and N- parameter measurements.

Figure 2 Output characteristics for a GaN HEMT with $\mathrm{V}_{\mathrm{GS}}$ from $-3.5 \mathrm{~V}$ to $0 \mathrm{~V}$ with $0.5 \mathrm{~V}$ step.

Figure 3 Equivalent circuit noise model.

Figure 4 Behavior of $\operatorname{Re}\left(\mathrm{Z}_{\mathrm{ij}}\right)$ before (a) and after (b) removing the extrinsic capacitance contributions as a function of the frequency from $500 \mathrm{MHz}$ to $50 \mathrm{GHz}$ for a GaN HEMT at $\mathrm{V}_{\mathrm{DS}}=0 \mathrm{~V}$ and $\mathrm{V}_{\mathrm{GS}}=-4 \mathrm{~V}$.

Figure 5 Extraction of the extrinsic resistances (a) and inductances (b) from the Z-parameters in the frequency range from $30 \mathrm{GHz}$ to $50 \mathrm{GHz}$ for a GaN HEMT at $\mathrm{V}_{\mathrm{DS}}=0 \mathrm{~V}$ and $\mathrm{V}_{\mathrm{GS}}=-4 \mathrm{~V}$.

Figure 6 Measured (blue solid line) and simulated (red dashed line) F50 versus the square of the frequency from $5 \mathrm{GHz}$ to $25 \mathrm{GHz}$ for a GaN HEMT at $\mathrm{V}_{\mathrm{DS}}=10 \mathrm{~V}$ and $\mathrm{IDS}_{\mathrm{DS}}=40 \mathrm{~mA}$.

Figure 7 Measured (blue solid lines) and simulated (red dashed lines) S-parameters from $0.1 \mathrm{GHz}$ to 50 $\mathrm{GHz}$ for a GaN HEMT at $\mathrm{V}_{\mathrm{DS}}=10 \mathrm{~V}$ and $\mathrm{IDS}_{\mathrm{DS}}=40 \mathrm{~mA}$.

Figure 8 Measured (blue solid lines) and simulated (red dashed lines) N-parameters from $5 \mathrm{GHz}$ to 25 $\mathrm{GHz}$ for a GaN HEMT at $\mathrm{V}_{\mathrm{DS}}=10 \mathrm{~V}$ and $\mathrm{I}_{\mathrm{DS}}=40 \mathrm{~mA}$ : minimum noise figure (a), equivalent noise resistance (b), and optimum reflection coefficient (c). 
This is the peer reviewed version of the following article, which has been published in final form 14 http://dx.doi.org/10.1002/mop.28983. This article may be used for non-commercial purposes in accordance with Wiley Terms and Conditions http://olabout.wiley.com/WileyCDA/Section/id-828039.html\#terms.

Figure 9 Measured (blue) and simulated (red) noise paraboloid at $20 \mathrm{GHz}$ for a GaN HEMT at $\mathrm{V}_{\mathrm{DS}}=10 \mathrm{~V}$ and $\mathrm{IDS}_{\mathrm{DS}}=40 \mathrm{~mA}$.

Figure 10 Measured (blue) and simulated (red) gain paraboloid at $20 \mathrm{GHz}$ for a GaN HEMT at $\mathrm{V}_{\mathrm{DS}}=10 \mathrm{~V}$ and $\mathrm{IDS}_{\mathrm{DS}}=40 \mathrm{~mA}$. 
This is the peer reviewed version of the following article, which has been published in final form 15 http://dx.doi.org/10.1002/mop.28983. This article may be used for non-commercial purposes in accordance with Wiley Terms and Conditions http://olabout.wiley.com/WileyCDA/Section/id-828039.htm/\#terms.

\section{FIGURES}

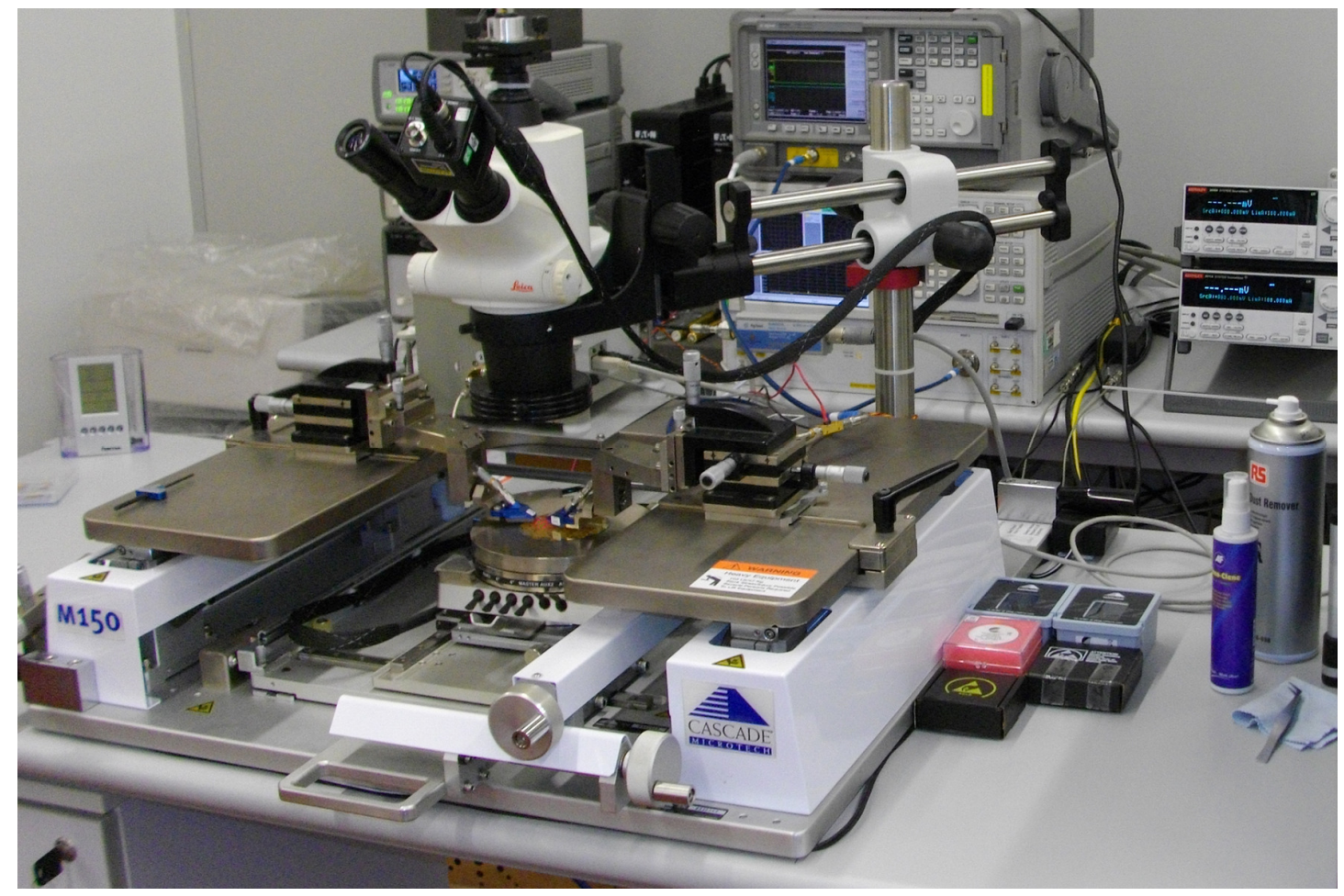

Fig. 1 
This is the peer reviewed version of the following article, which has been published in final form 16 http://dx.doi.org/10.1002/mop.28983. This article may be used for non-commercial purposes in accordance with Wiley Terms and Conditions http://olabout.wiley.com/WileyCDA/Section/id-828039.html\#terms.

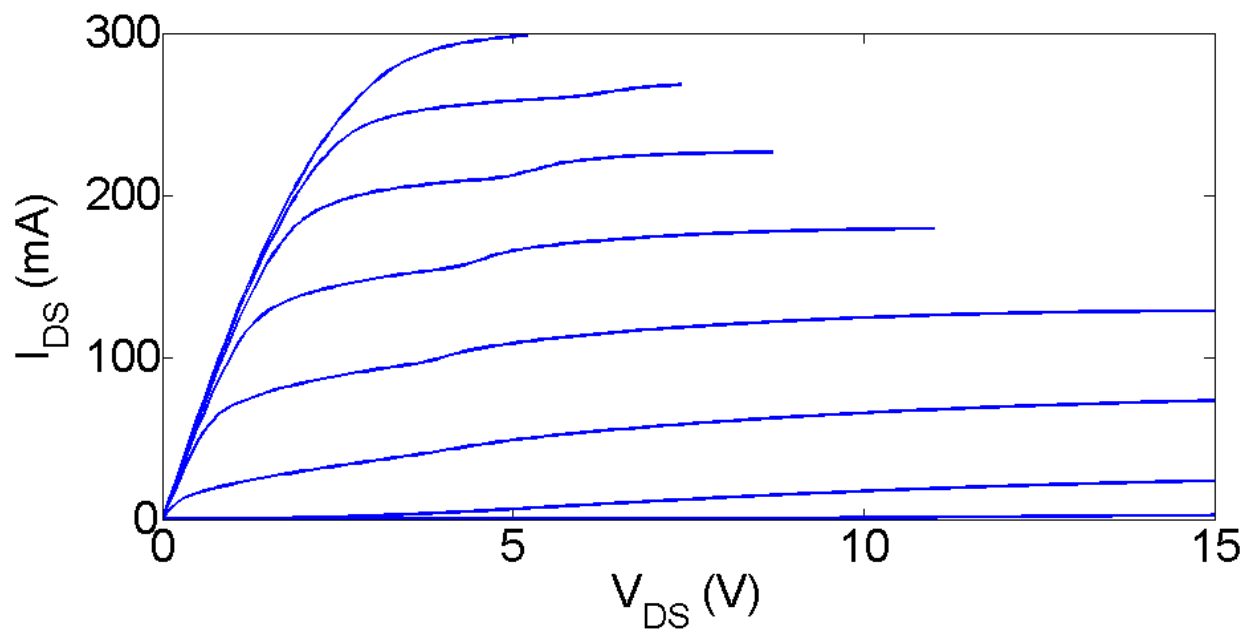

Fig. 2 
This is the peer reviewed version of the following article, which has been published in final form 17 http://dx.doi.org/10.1002/mop.28983. This article may be used for non-commercial purposes in accordance with Wiley Terms and Conditions http://olabout.wiley.com/WileyCDA/Section/id-828039.html\#terms.

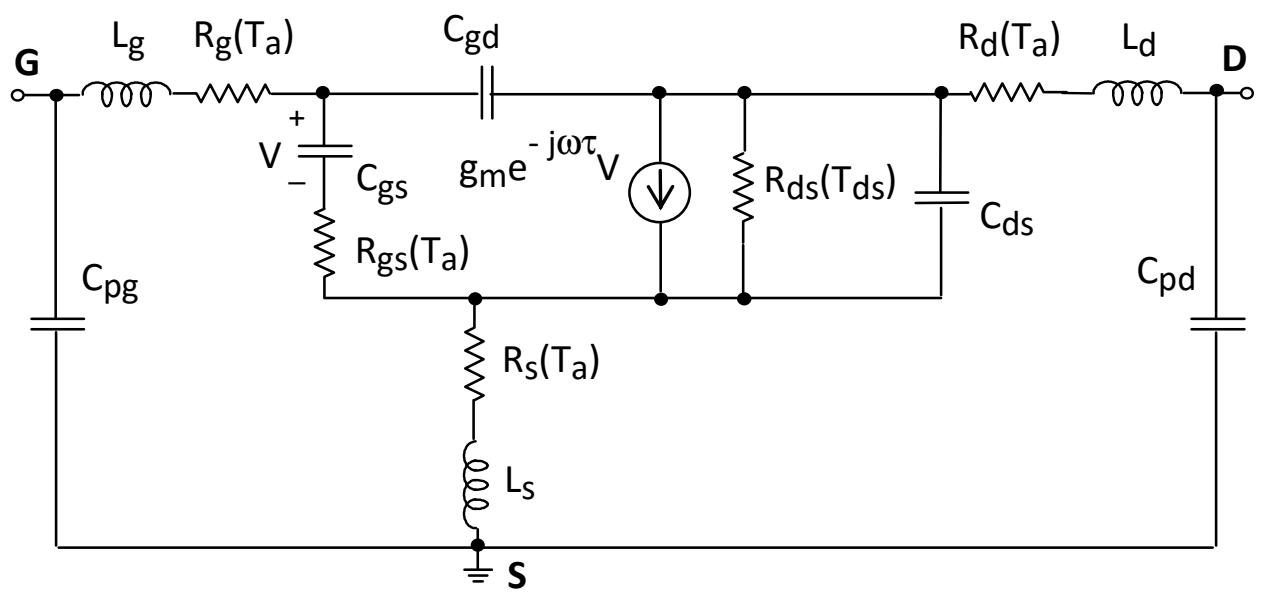

Fig. 3 
This is the peer reviewed version of the following article, which has been published in final form 18 http://dx.doi.org/10.1002/mop.28983. This article may be used for non-commercial purposes in accordance with Wiley Terms and Conditions http://olabout.wiley.com/WileyCDA/Section/id-828039.html\#terms.

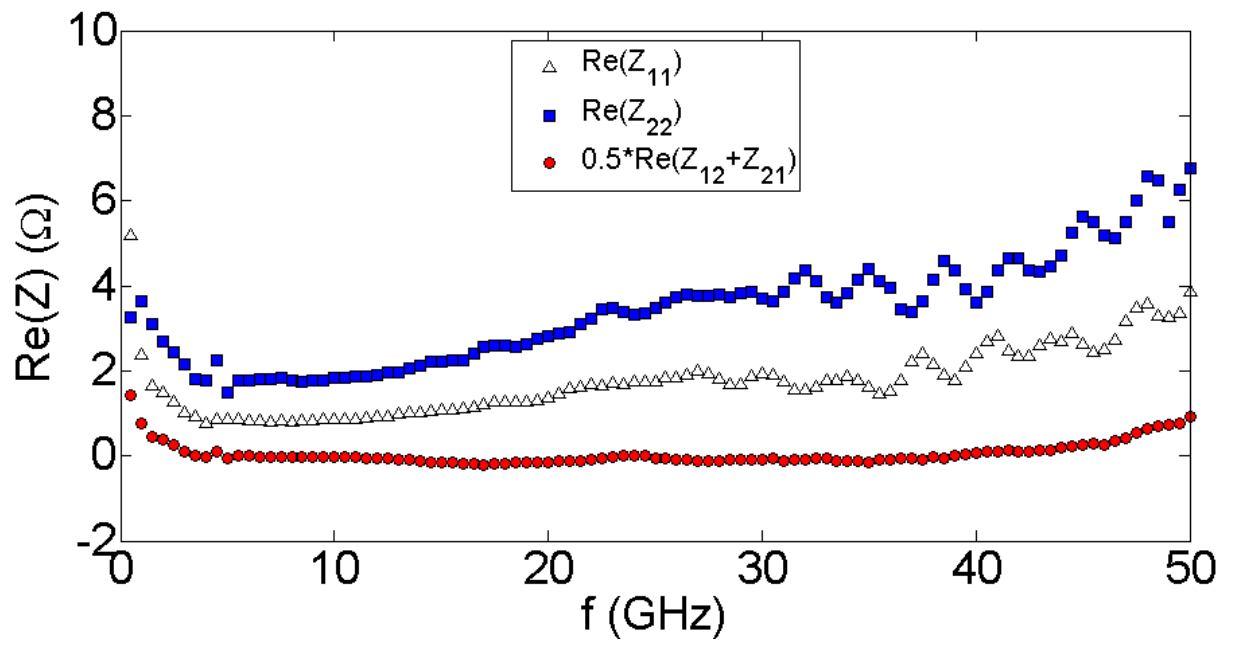

(a)

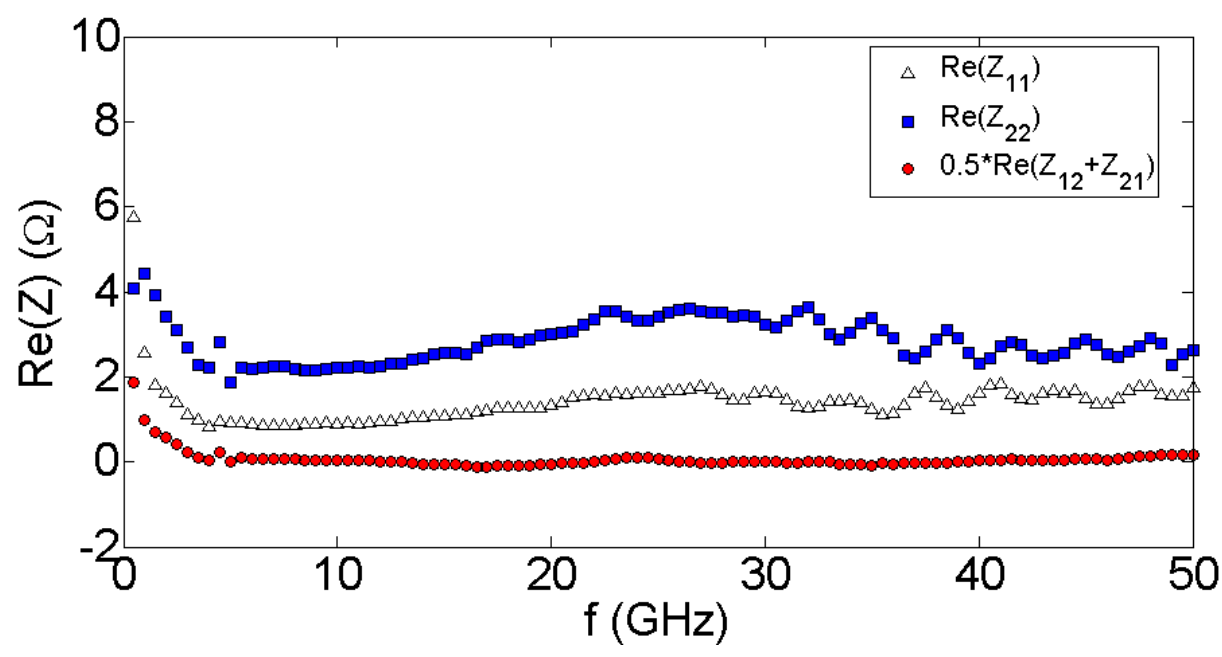

(b)

Fig. 4 


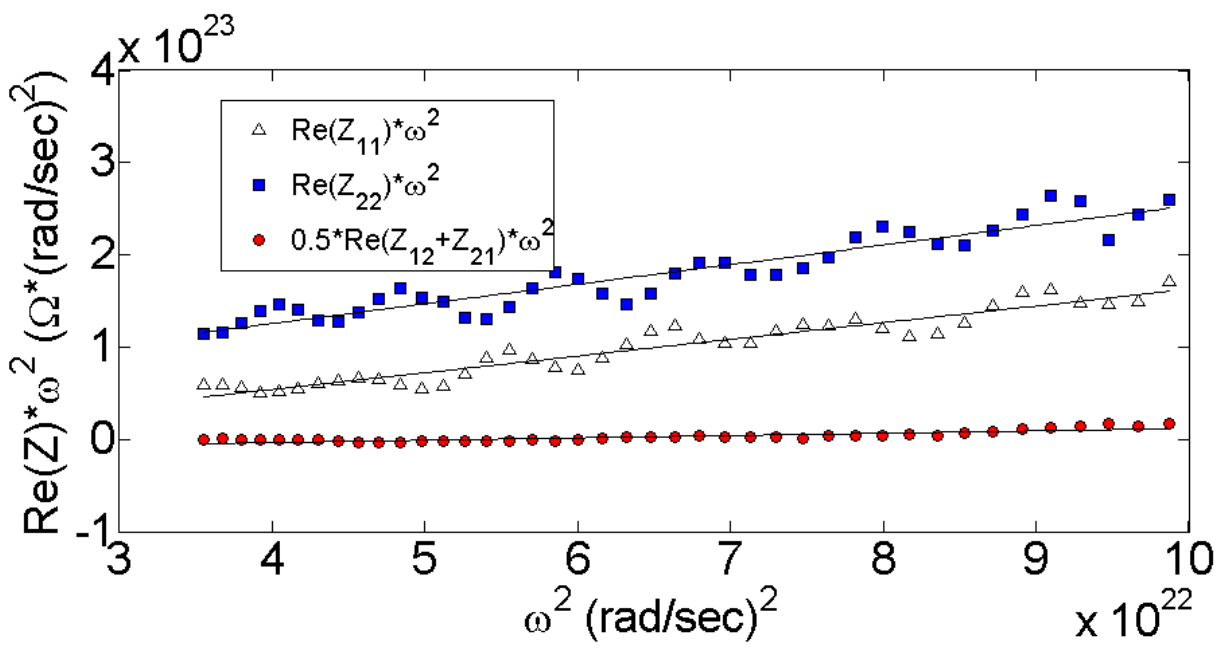

(a)

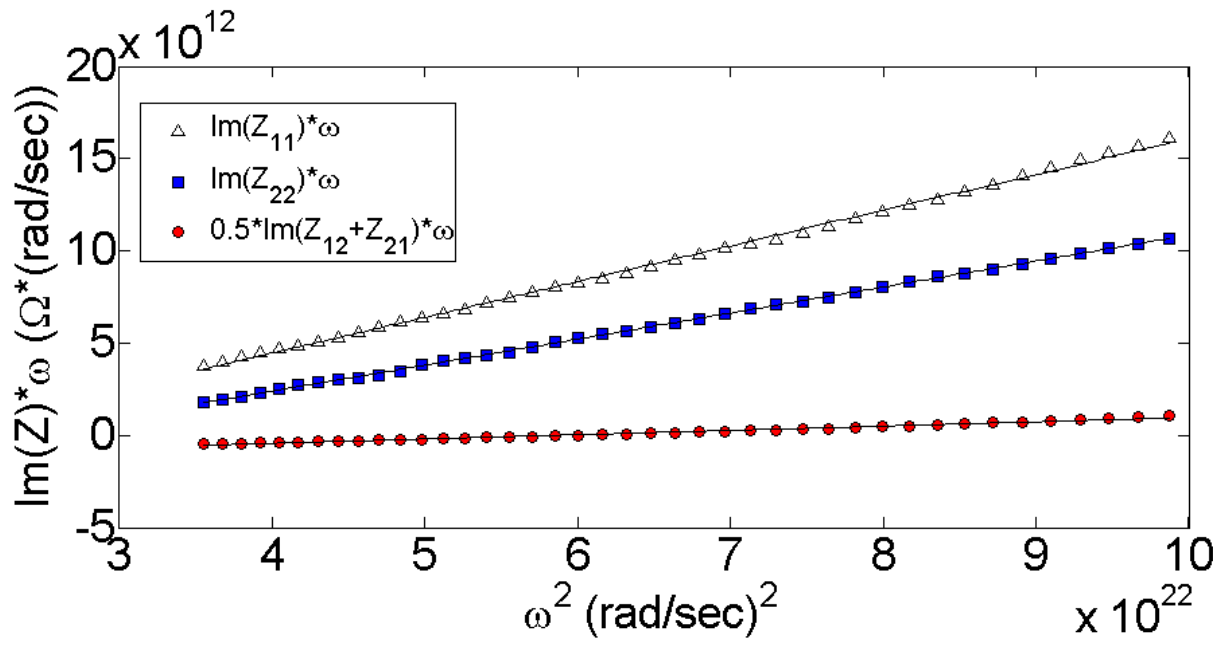

(b)

Fig. 5 
This is the peer reviewed version of the following article, which has been published in final form 20 http://dx.doi.org/10.1002/mop.28983. This article may be used for non-commercial purposes in accordance with Wiley Terms and Conditions http://olabout.wiley.com/WileyCDA/Section/id-828039.html\#terms.

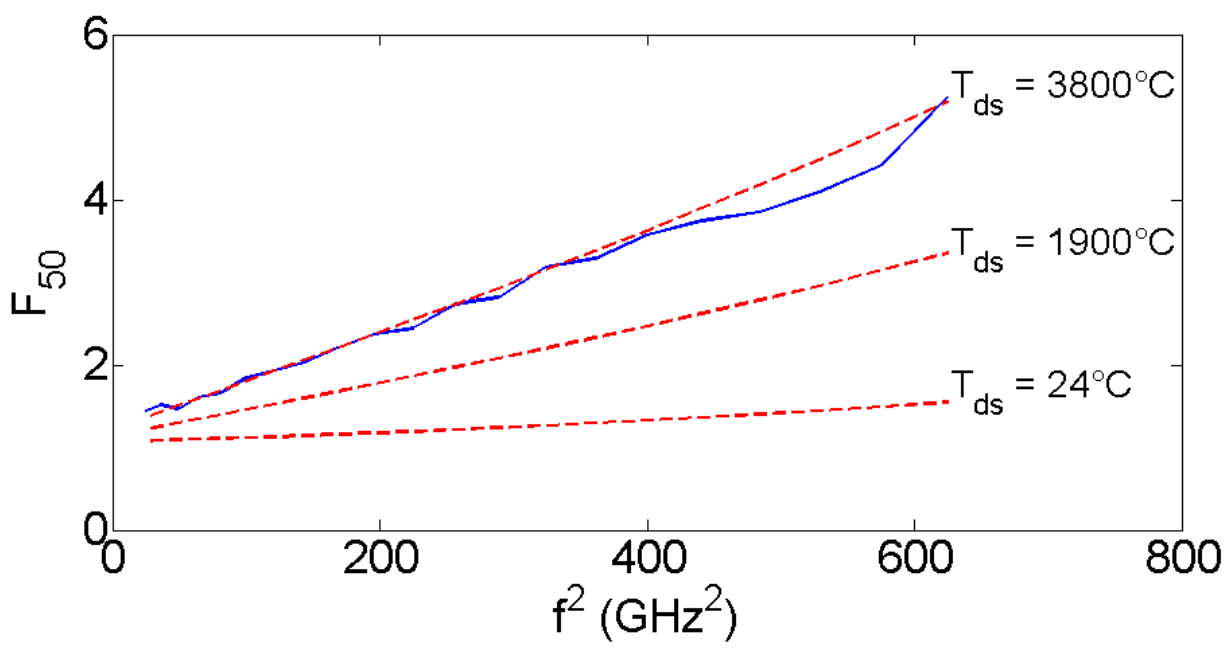

Fig. 6 
This is the peer reviewed version of the following article, which has been published in final form 21 http://dx.doi.org/10.1002/mop.28983. This article may be used for non-commercial purposes in accordance with Wiley Terms and Conditions http://olabout.wiley.com/WileyCDA/Section/id-828039.html\#terms.
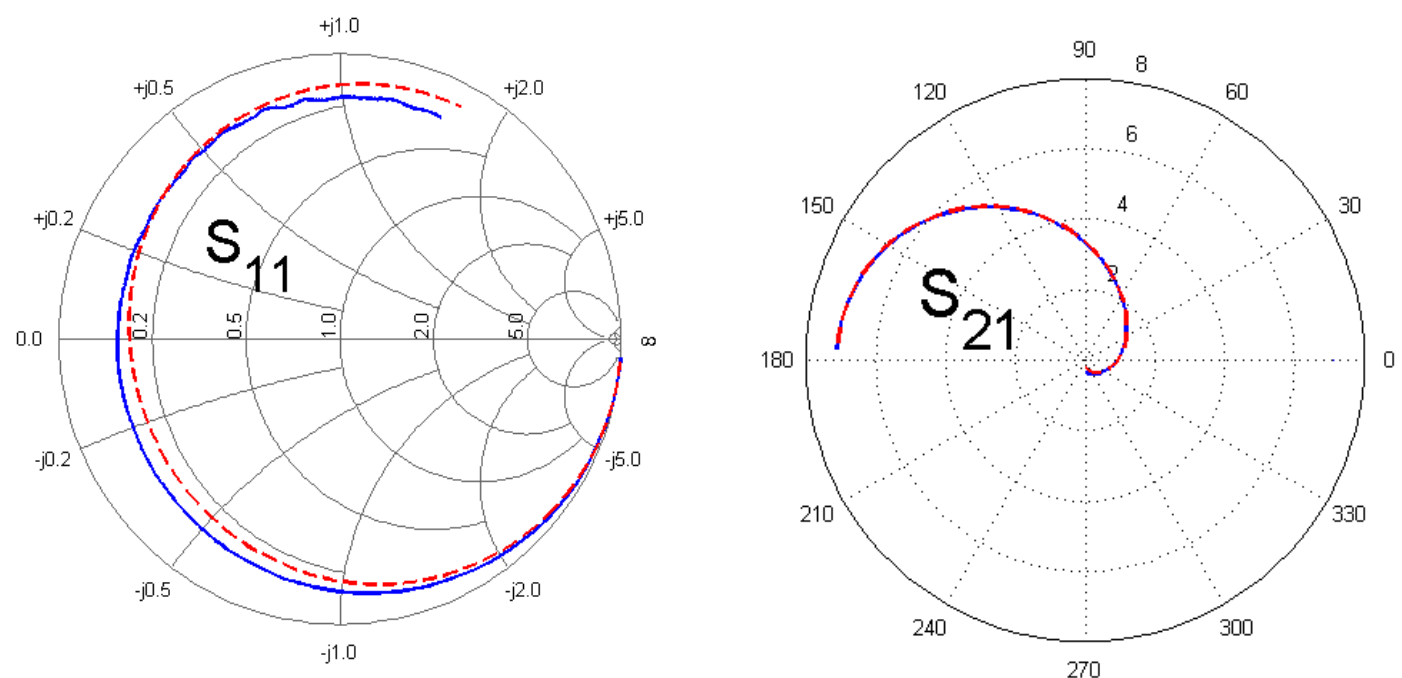

(a)

(b)
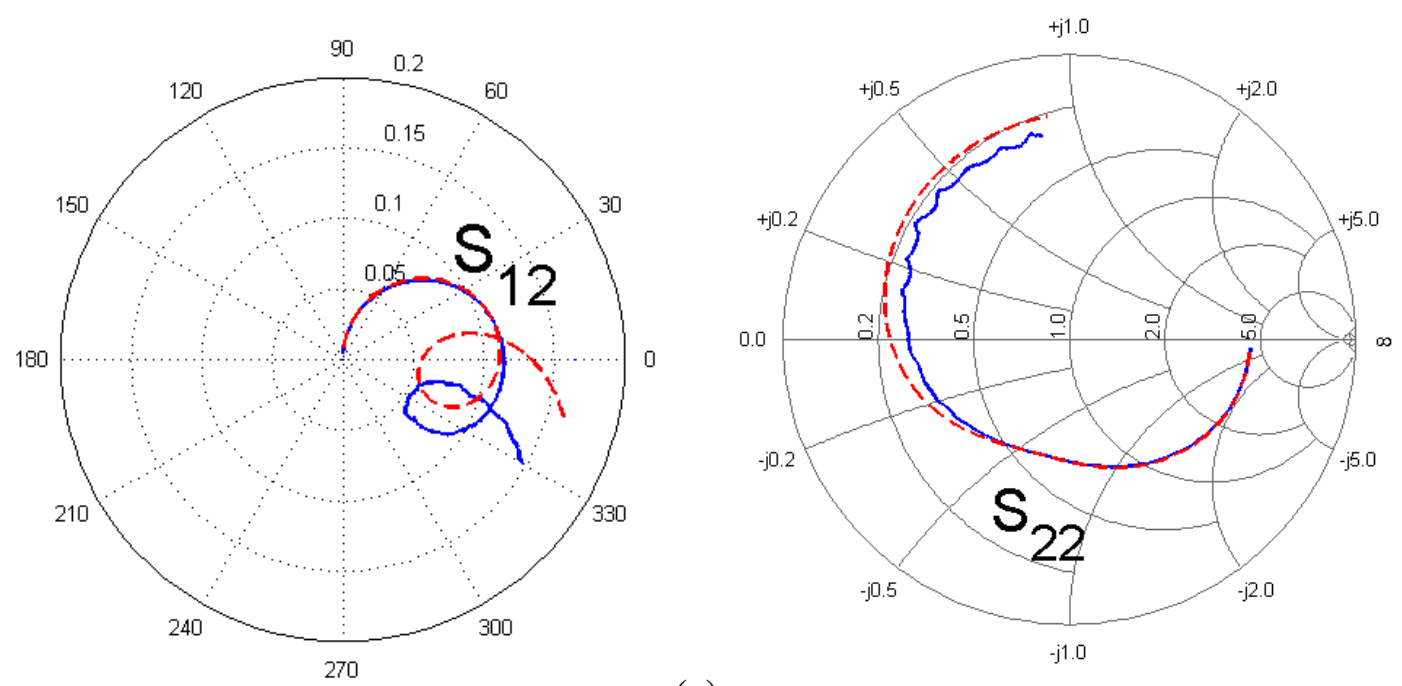

(c)

(d)

Fig. 7 
This is the peer reviewed version of the following article, which has been published in final form 22 http://dx.doi.org/10.1002/mop.28983. This article may be used for non-commercial purposes in accordance with Wiley Terms and Conditions http://olabout.wiley.com/WileyCDA/Section/id-828039.htm/\#terms.

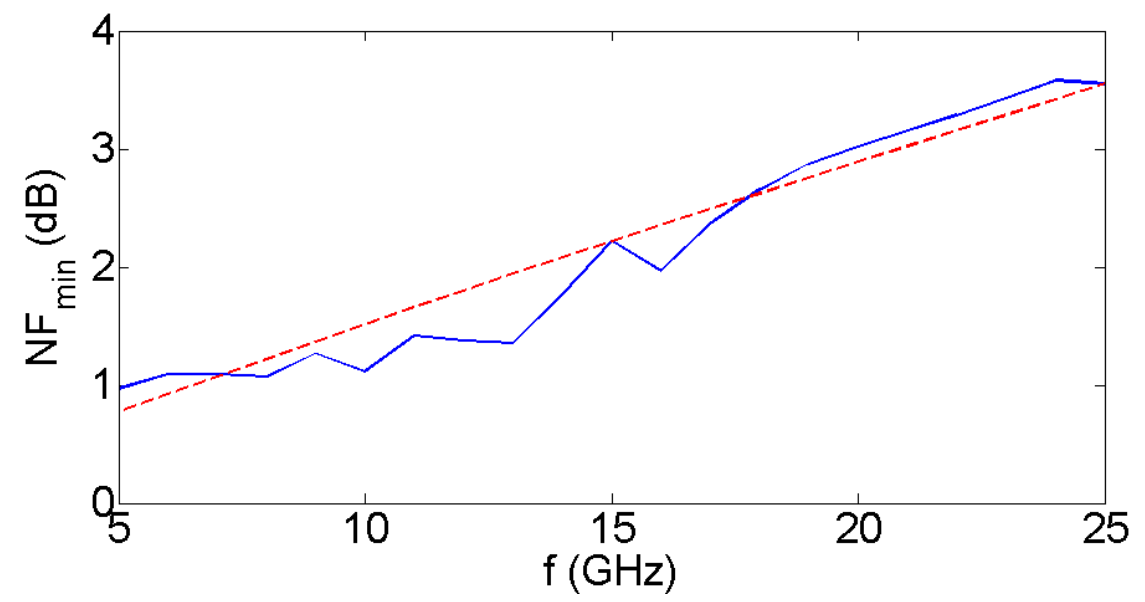

(a)

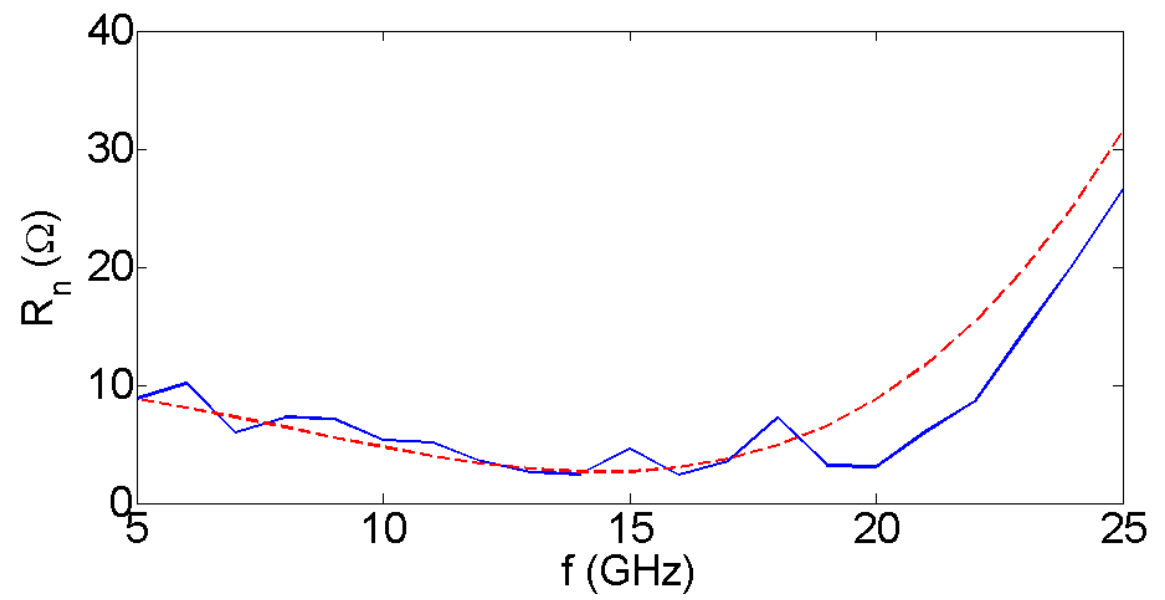

(b)

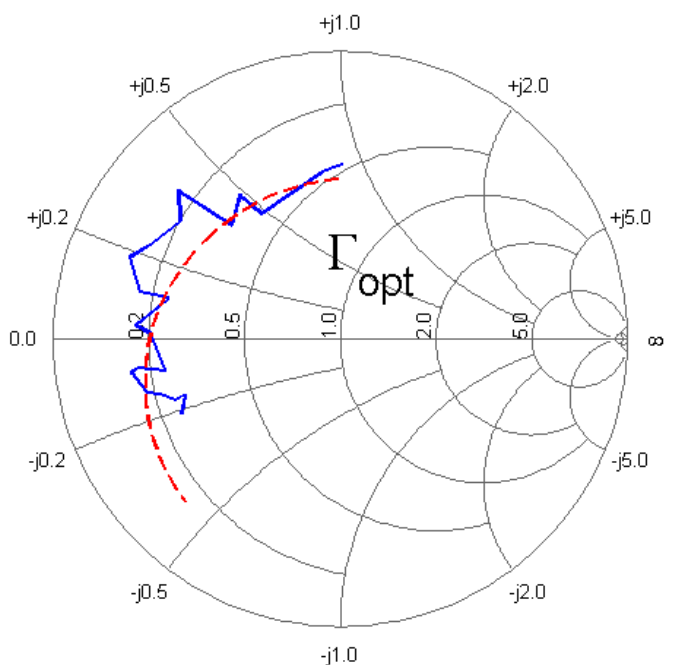

(c)

Fig. 8 
This is the peer reviewed version of the following article, which has been published in final form 23 http://dx.doi.org/10.1002/mop.28983. This article may be used for non-commercial purposes in accordance with Wiley Terms and Conditions http://olabout.wiley.com/WileyCDA/Section/id-828039.html\#terms.

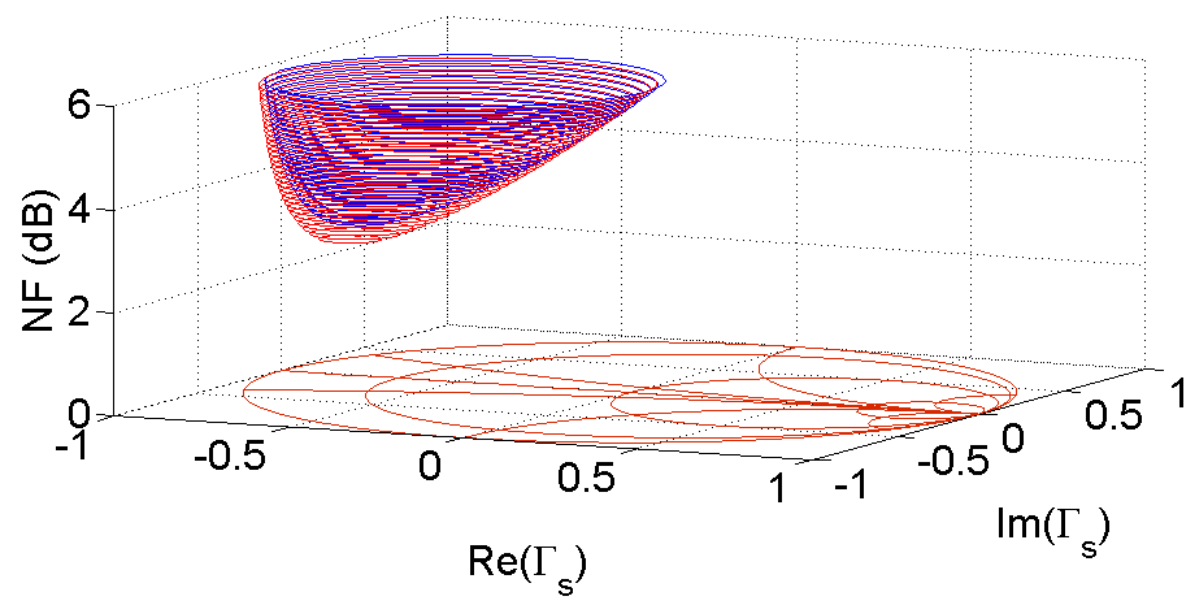

Fig. 9 
This is the peer reviewed version of the following article, which has been published in final form 24 http://dx.doi.org/10.1002/mop.28983. This article may be used for non-commercial purposes in accordance with Wiley Terms and Conditions http://olabout.wiley.com/WileyCDA/Section/id-828039.htm/\#terms.

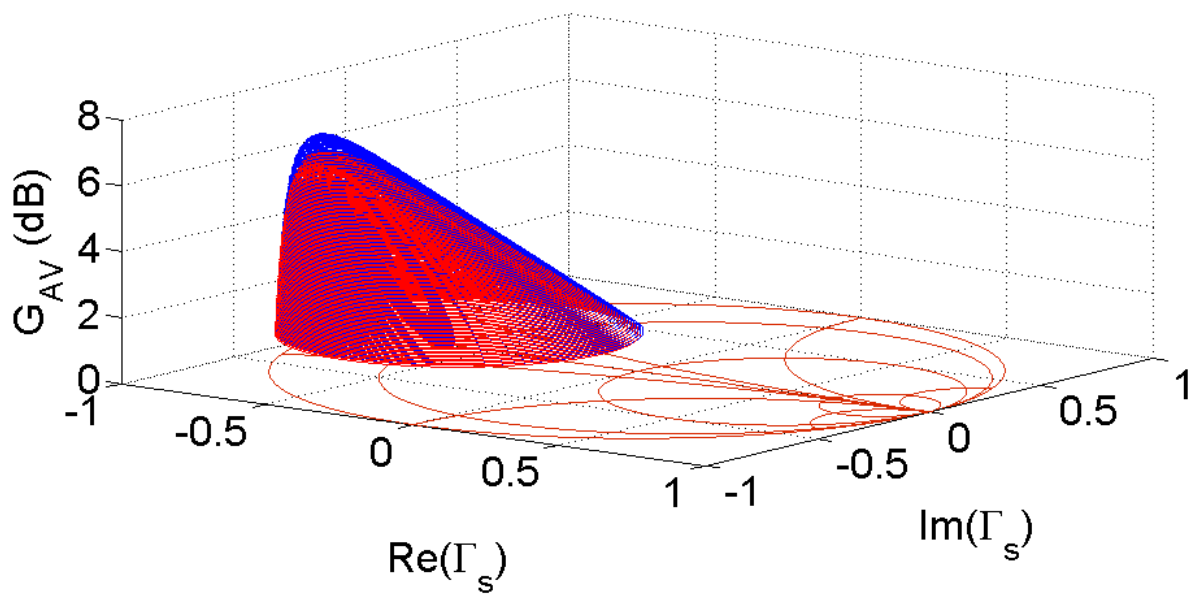

Fig. 10 
This is the peer reviewed version of the following article, which has been published in final form 25 http://dx.doi.org/10.1002/mop.28983. This article may be used for non-commercial purposes in accordance with Wiley Terms and Conditions http://olabout.wiley.com/WileyCDA/Section/id-828039.html\#terms.

\section{TABLES}

\section{TABLE I}

Values of The Equivalent Circuit Elements

\begin{tabular}{|c|c|}
\hline $\mathrm{C}_{\mathrm{pg}}(\mathrm{fF})$ & 20 \\
\hline $\mathrm{C}_{\mathrm{pd}}(\mathrm{fF})$ & 35 \\
\hline $\mathrm{L}_{\mathrm{g}}(\mathrm{pH})$ & 170.1 \\
\hline $\mathrm{L}_{\mathrm{s}}(\mathrm{pH})$ & 23.3 \\
\hline $\mathrm{L}_{\mathrm{d}}(\mathrm{pH})$ & 117.6 \\
\hline $\mathrm{R}_{\mathrm{g}}(\Omega)$ & 1.8 \\
\hline $\mathrm{R}_{\mathrm{s}}(\Omega)$ & 0.3 \\
\hline $\mathrm{R}_{\mathrm{d}}(\Omega)$ & 2.1 \\
\hline $\mathrm{C}_{\mathrm{gs}}(\mathrm{fF})$ & 549.2 \\
\hline $\mathrm{C}_{\mathrm{gd}}(\mathrm{fF})$ & 87.4 \\
\hline $\mathrm{C}_{\mathrm{ds}}(\mathrm{fF})$ & 174.3 \\
\hline $\mathrm{R}_{\mathrm{ds}}(\Omega)$ & 213.5 \\
\hline $\mathrm{R}_{\mathrm{gs}}(\Omega)$ & 0.5 \\
\hline $\mathrm{g}_{\mathrm{m}}(\mathrm{mS})$ & 90.3 \\
\hline$\tau(\mathrm{ps})$ & 2.3 \\
\hline
\end{tabular}

